\title{
TECHNICAL MODIFICATION OF THE METAMAX II PORTABLE METABOLIC ANALYSER FOR OPERATION WITH A BREATHING APPARATUS
}

\author{
J.I. Medbø ${ }^{1}$, O.M. Synnes ${ }^{1}$, E.D. von Heimburg ${ }^{2}$ \\ ${ }^{1}$ National Institute of Occupational Health, Oslo, Norway \\ ${ }^{2}$ Faculty of Teacher Education, Department Physical Education and Sport, \\ North-Trøndelag University College, Levanger, Norway
}

\begin{abstract}
The $\mathrm{O}_{2}$ uptake of firefighters working in hot and polluted environment is not known. The portable Metamax II might measure the $\mathrm{O}_{2}$ uptake of firefighters using a breathing apparatus. However, the Metamax requires an inspiration signal between two expirations to work properly. When a firefighter inspires from bottles with pressurised air, the inspired air cannot readily be passed through a metabolic analyser. Expired air is on the other hand released to the surroundings and may be sampled for further analyses. In addition, the Metamax II does not tolerate heat, and gases at the scene of fire may damage its delicate sensors. We have modified the Metamax II, producing an artificial inspiration signal after every expiration. We have also protected the instrument from heat at the scene of fire. Expired air was sampled from exercising subjects using a breathing apparatus. The Metamax II instrument was run in the normal and modified modes while the instrument's reported $\mathrm{O}_{2}$ uptake was recorded. Control experiments showed that without an inspiration signal, the instrument did not work reliably. In a typical experiment the reported $\mathrm{O}_{2}$ uptake was only $50 \%$ of the true value. In further experiments an artificial inspiration signal was sent to the main unit after every expiration. Then the instrument worked properly although only expired air passed through the Metamax' breathing valve. With proper modifications of the Metamax II, the instrument worked well even if only expired air passed through the breathing valve. The valve may thus be mounted on the outlet of a
\end{abstract}


firefighter's breathing mask. The instrument can readily be protected from heat at the scene of fire and thus be used to measure the $\mathrm{O}_{2}$ uptake of smoke divers during realistic exercises in hot and polluted environments.

Key words: Metamax II; modification; metabolic analyzer; oxygen consumption, oxygen uptake; fire-fighting; smoke diving.

\section{INTRODUCTION}

Physically demanding fire-fighting is often carried out in hot and polluted environments. For scientific examination of the physical demand, direct measurements of the $\mathrm{O}_{2}$ uptake are needed. This can in principle be done using modern, electronic equipment. However, such instruments do not tolerate high temperatures, and polluted air may affect the delicate sensors, which make direct measurements difficult $[5,10]$. Since the instrument needs protection beyond that of the standard housing when used in such extreme conditions, no studies have to our knowledge measured the $\mathrm{O}_{2}$ uptake of firefighters using a breathing apparatus, working in hot and polluted environments.

A fire-fighter is usually dressed up as a smoke diver, using protective clothing including a face mask with dedicated valves, inspiring from bottles with pressurized air, while expired air is released to the surroundings through the mask's outlet valve. Thus, inspired air is not readily available for analyses, while the expired air may be sampled for further analyses. We have in this study examined the Metamax II metabolic analyzer for use with a breathing apparatus and a face mask in hot conditions. While the Metamax calculates the $\mathrm{O}_{2}$ uptake from measurements on expired air only, the instrument may need an inspiration signal between two expirations to work properly according to information from the manufacturer. Since only expired air is available for analyses on smoke divers, we had to modify the instrument, producing an artificial inspiration signal after every expiration. We have in addition improved the thermal and mechanical protection since the standard housing may not protect against the high temperatures and possibly hard physical contact met when working in the heat or with heavy tools during fire-fighting. We here describe these modifications and show that the instrument worked properly. 


\section{METHODS}

\section{The Metamax II instrument}

Basic design and principles of operation

The Metamax II instrument (Cortex Biophysic, Leipzig, Germany; serial number of our instrument: MII 63 229901) consists of a main unit housing sensors analyzing fractions of $\mathrm{O}_{2}$ and $\mathrm{CO}_{2}$ in sampled air, a built-in barometer, a display and control buttons, electronics and software for analysing the raw data, and connections for other parts (the Triple $\mathrm{V}$ breathing valve, power supply) as well as for communication (telemetry, PC through a common RS 232 port). Respired air is measured by the Triple $\mathrm{V}$ mounted on a mouth piece or a face mask. The Triple V is a turbine-type flow sensor. More specifically, when air flows through the turbine with twisted stators, air drives a lightweight rotor $(20 \mathrm{mg})$ that rotates in close proportion to the amount of air passed through. The rotor's movements are recorded by two sets of infrared photodetectors organized so that both the volume and direction of the flow are determined, and the signals are fed to the main unit. In addition a small amount of expired air is sampled from the turbine housing during every expiration and sucked to the main unit for analyses of $\mathrm{O}_{2}$ and $\mathrm{CO}_{2}$ through a dedicated line. There is no air sampling during inspirations. During field studies this unit is often carried in a harness serving as a small back-pack. The whole instrument carried including accessories for field experiments weighed $1.9 \mathrm{~kg}$ in our study. The instrument has been examined elsewhere and found to work properly during normal use $[8,9]$.

\section{Technical details of the flow recordings}

The cable connecting the Triple $\mathrm{V}$ to the main unit contains eight wires, of which only five are being used according directions provided by the manufacturer ("Anschluss Triple- $\mathrm{V}$ am Metalyzer und Metamax II"). Wire 3 (called flow 1 by the manufacturer), and wire 4 (called flow 2) are of particular interest here. Wire 1 is ground, and wire 6 provides voltage supply that appeared to be only $\approx 2.7 \mathrm{~V}$; this was too low to give a reliable power supply to the electronics we used (see below for further details). Wire 8 of $\approx 3.1 \mathrm{~V}$ is according to the manufacturer connected to ground thru a $9.1 \mathrm{k} \Omega$ resistor, apparently to detect a proper connection.

The optical sensors have two infrared photodiodes, each with a corresponding photocell. During inspiration the signal from flow 
1 leads that of flow 2 by $25 \%$ of a full square wave cycle (compatible with $45^{\circ}$ displacement around the arc), while during expiration the sequence is reversed. This allows the software to distinguish between expirations and inspirations.

We purchased an extension cable to the Triple V (Extension cable DVT/Triple V for volume transducer 130-01-022). The extension cable was cut in two, and each wire was freed and soldered to a small circuit board. The voltage of each wire and the signals between the Triple $\mathrm{V}$ and the main unit were read off on an ordinary oscilloscope (Mixed signal oscilloscope 54645D, Hewlett Packard). These recordings verified that that during inspiration the signal of "flow 1" (wire 3 ) is ahead of that of "flow 2" (wire 4), and that the sequence is reversed during expiration as described above. When the light beam was cut, a high voltage of $\approx 4.8 \mathrm{~V}$ was recorded, while when light hit the photocell, a low voltage of $\approx 0.2 \mathrm{~V}$ was recorded. This suggests that the instrument uses standard TTL (transistor-transistor logic) electronics using a voltage divisor in the main unit and further that the photocell works as a phototransistor pulling down the voltage to a low level when being illuminated. Moreover, our recordings also showed that during use each wire conducts a square wave signal to the main instrument.

Making a false inspiration signal

A Pic 16F 628/20 microprocessor (Microchip Technology, Chandler, AZ, USA) was mounted on the circuit board. The Pic 16F microprocessor has altogether 18 pins named $\mathrm{A} 0-\mathrm{A} 7, \mathrm{~B} 0-\mathrm{B} 7$ and in addition the two used for voltage supply and ground connection. The processor was programmed in MBasic Professional (B0024, Basic Micro IDE, Farmington Hills, MI, USA) as outlined below.

Since during normal use voltage is supplied to the two flow wires from the main unit and since this supply was broken when the cut extension cable was used, we provided a $5 \mathrm{~V}$ supply through $\approx 10 \mathrm{k} \Omega$ resistors to wires 3 and 4 (flow 1 and 2) on the Triple V-side of the circuit board from the voltage supply described below. The signals on flow 1 and flow 2 from the Triple V were connected to pins A2 and A3 of the processor. Pins B1 and B2, respectively, were connected to the corresponding wires on the Metamax side of the board. During expiration the signals on $\mathrm{A} 2$ and $\mathrm{A} 3$ were read continuously, and the signal of pins $\mathrm{B} 1$ and $\mathrm{B} 2$ were programmed to match those of $\mathrm{A} 2$ and A3, respectively. Thus, during expiration the microprocessor let the signal pass thru. Separate examinations showed that the microprocessor 
reproduced the square-wave signals even during maximal expirations. If no change on pin A3 was recorded during a period of $0.3 \mathrm{~s}$, an end-ofexpiration-flag was set, and the microprocessor then generated a simulated inspiration signal with the following pattern: B1 (flow 1) was set high, and after a pause of $3 \mathrm{~ms}$ B2 (flow 2) was set high. After a $4 \mathrm{~ms}$ pause B1 was set low, and after a new pause of $3 \mathrm{~ms} \mathrm{~B} 2$ was set low. After $4 \mathrm{~ms} \mathrm{B1}$ was again set high. This sequence was repeated 25 times, taking altogether $0.37 \mathrm{~s}$ (including some initial commands).

The program included controls of a valid expiration and of whether an inspiration had been generated recently. The circuit board and wiring also included two standard LED connected to pins B3 and B4 of the processor thru resistors of $\approx 300 \Omega$. These diodes were lit during expiration (green, B3) and when the inspiration signal was generated (red, B4). That allowed us to follow the operation of the program both during development and use.

The Pic microprocessor was supplied by power by a standard commercial $9 \mathrm{~V}$ block battery (called 6AM6, 6LR61, or 6LF22 by different manufacturers and classifications) through a 7805 (TO92) $5 \mathrm{~V}$ regulator. A battery lasted at least $3 \mathrm{~d}$ during continuous use before the voltage dropped to $5 \mathrm{~V}$ and the battery had to be replaced. The circuit board is outlined in Figure 1. 


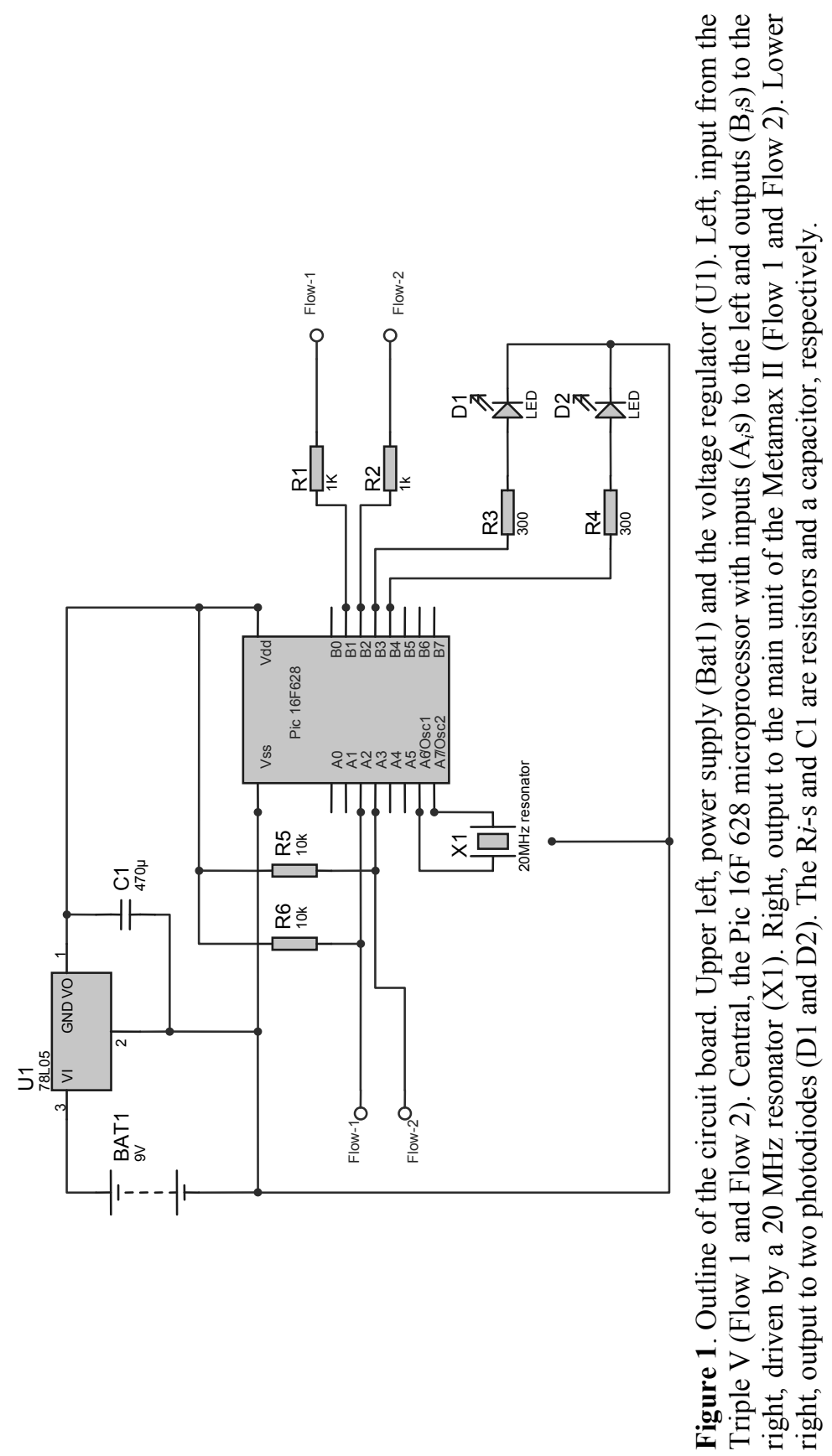




\section{A more robust expiration signal}

During the development we learned that one single pulse of the type "flow 2-flow 1" (an expiration-sequence) from the Triple V to the Metamax' main unit was enough to start the pump for sampling of gas to the main unit and thus to record an "expiration" in the Metamax built-in software. Since such pulses occasionally appeared (passive rotation of the rotor, for example because the subject moved the head, or even by a heart beat at rest), we realized that the system was hypersensitive. To reduce that problem we rewrote the program, requiring four such "flow 2-flow 1"-sequences before an expiration signal was let thru. Since this restriction removed four (half) rotations of the turbine fan and thus reduced the instrument's recorded expired volume correspondingly, four extra pulses were added to the pulse sequence to the main unit once expiration had started.

\section{Connecting the Triple $V$ to the Interspiro face mask}

The outlet of the Interspiro face mask is covered by a hollow, open cylinder $\approx 35 \mathrm{~mm}$ high and with an outer diameter of $\approx 78 \mathrm{~mm}$ that houses the outlet's valve system. This cylinder thus serves as a cap (here called cap A). The wall at the open end of the cylinder has threads that allow the housing with the valves to be screwed onto the face mask. There is a slit $\approx 5.6 \mathrm{~mm}$ wide around the cylinder wall that allows air to be released, and this outlet is protected by a removable ring $\approx 3 \mathrm{~mm}$ thick and $\approx 14 \mathrm{~mm}$ wide. To sample expired air the protective ring was removed, and a hollow, open cylindrical cap (called cap B) being $41 \mathrm{~mm}$ high and with an outer diameter of $90 \mathrm{~mm}$, was mounted around cap A. Gaps between the two caps were closed by commercial silicon glue. Cylinder B had a hole with a diameter of $\approx 30 \mathrm{~mm}$ in the side wall. A pipe $24 \mathrm{~mm}$ long was mounted in that hole to serve as a spout. At its open end this spout had an inner diameter of $\approx 31.3 \mathrm{~mm}$, narrowing in by $3^{\circ}$ to match the conically shaped spout on the inlet of the Triple $\mathrm{V}$, thus allowing a tight fit. This modification of the outlet of the Interspiro face mask allowed us to sample and analyse expired air by the Metamax (Figure 2). All parts described above were made of PVC plastic. 


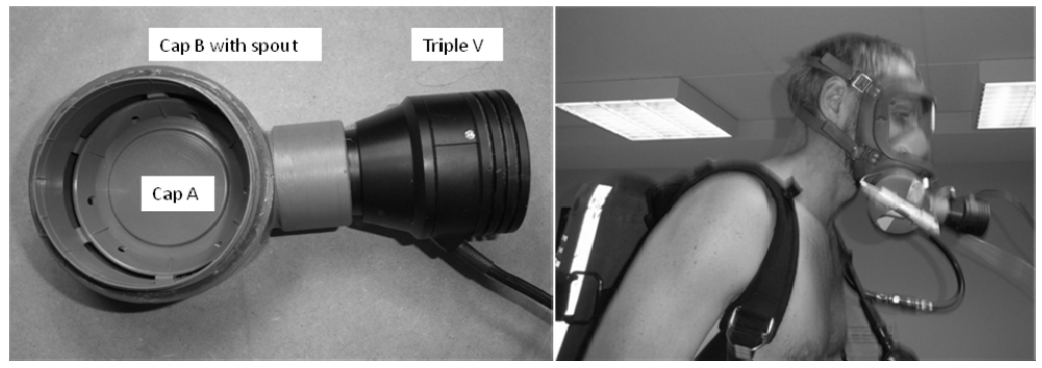

Figure 2. Photos of connections between the Interspiro face mask and the Metamax II. Left, inside of cap A of the outlet of the Interspiro face mask. Holes in the side wall allow air to escape. Cap B with spout around cap A collects released air, leading air through the spout to the Triple $\mathrm{V}$ of the Metamax. Right, a subject walking on the treadmill while testing the equipment. The subject is carrying bottles with pressurized air in a harness on his back. Air is led from the bottles to the Interspiro face mask thru a high-pressure hose. The connections shown in detail on the left are mounted on the outlet of the face mask. The white column on cap B contains drierite $\left(\mathrm{CaSO}_{4}\right)$ that absorbs water vapour from air led to the main unit of the Metamax II for analyses of fractions of $\mathrm{O}_{2}$ and $\mathrm{CO}_{2}$.

\section{Heat protection of the Metamax}

To protect the equipments against heat and mechanical impacts, the main unit was placed in a box of five-layered plywood filled with an isolating material (Mineral fiber, Protecta, Tønsberg, Norway). The lines connecting the main unit and the Triple $\mathrm{V}$ sensor were likewise isolated by a wool stocking tube covered by the same cotton as being used in the firefighters' protective clothings and using fiber tape as outer cover. Measurements showed that even after $8 \mathrm{~min}$ in a heat chamber $\left(T \geq 140^{\circ} \mathrm{C}\right)$, the temperature in the box never exceeded $25{ }^{\circ} \mathrm{C}$, and the temperature inside the stocking tube was $\leq 40{ }^{\circ} \mathrm{C}$. The box of plywood with additional insulation and straps weighed $3.7 \mathrm{~kg}$. Thus, the box with insulation and the Metamax II with accessories weighed altogether $5.6 \mathrm{~kg}$. 


\section{Experiments}

Two informed volunteers (staff members) who knew their rights, served as subjects. In one study the subject ran on the treadmill at constant speed and inclination while the $\mathrm{O}_{2}$ uptake was alternately measured by the Metamax II in the normal mode or when connecting the Triple $\mathrm{V}$ to the outlet of a three-way breathing valve. In the latter case only expired air passed through the turbine.

In further experiments the subject cycled twice on separate days on a Krogh-type cycle ergometer [6] at constant power that was increased stepwise at 5 min intervals. Respiratory parameters including the $\mathrm{O}_{2}$ uptake were measured by the Metamax II. One day the instrument was run in the normal mode. The other day the subjects wore an Interspiro face mask, inspiring from bottles with high-pressurized air. After each expiration the microprocessor generated an artificial inspiration signal that was fed to the main unit of the Metamax II (see above for further details).

\section{RESULTS}

The subject ran on the treadmill at constant speed while the $\mathrm{O}_{2}$ uptake was measured by the Metamax II. When the instrument was run in the normal mode, the reported $\mathrm{O}_{2}$ uptake varied by $2 \%$ between $10 \mathrm{~s}$ intervals once a steady state level was reached (open symbols in Figure 3). When only expired air passed thru the Triple $\mathrm{V}$ breathing valve, the reported $\mathrm{O}_{2}$ uptake fell by around $50 \%$, and the reported value varied considerably (filled symbols in Figure. 3).

In further experiments the conditions mimicked that of smoke diving. When the subject inspired from a breathing apparatus, an artificial inspiration signal was generated after every expiration as explained in further detail in the method section. The reported $\mathrm{O}_{2}$ uptake did not differ systematically from that when the Metamax II instrument was used the normal way (Figure 4). The mean absolute deviation was $24 \pm 10 \mu \mathrm{mol} / \mathrm{s}(1 \%)$. The lung ventilation that in separate control experiments was at least $30 \%$ too low when the instrument received no inspiration signal did not differ systematically between the two experimental conditions. The mean absolute deviation was $2.0 \pm 0.8 \mathrm{~L} / \mathrm{min}(<5 \%)$. 


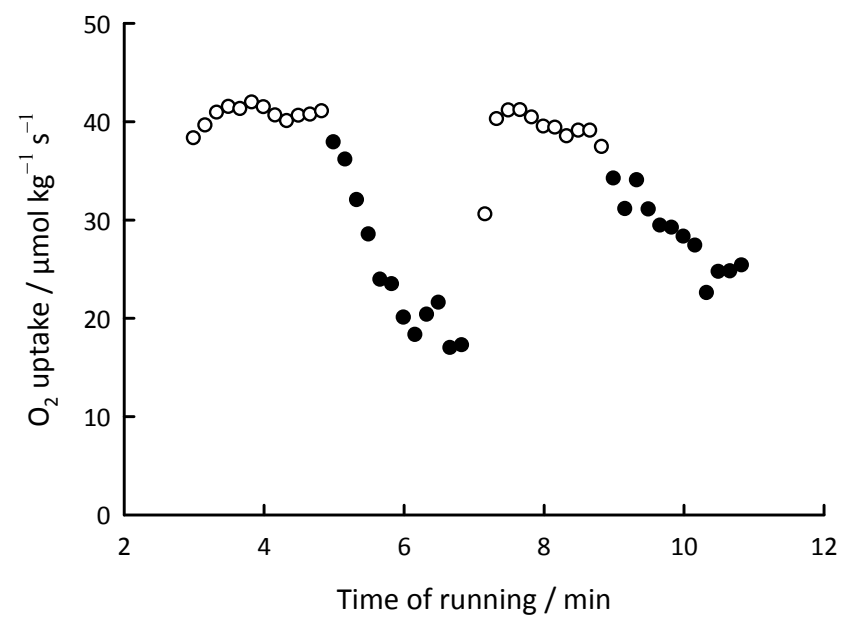

Figure 3. A well-trained middle-aged man ran on the treadmill at $3.33 \mathrm{~m} / \mathrm{s}(12 \mathrm{~km} / \mathrm{h})$ at $5 \%$ inclination. The $\mathrm{O}_{2}$ uptake was measured continuously by the Metamax II and reported in $10 \mathrm{~s}$ intervals. When the instrument was run in its normal mode where both inspired and expired air passed thru the Triple $\mathrm{V}$ breathing valve ( $O$, open symbols), the reported $\mathrm{O}_{2}$ uptake averaged $40.4 \mu \mathrm{mol} / \mathrm{kg} / \mathrm{s}$ with a standard deviation between $10 \mathrm{~s}$ intervals of $0.8 \mu \mathrm{mol} / \mathrm{kg} / \mathrm{s}(2 \%)$. When the subject breathed through a three-way valve where the Triple $\mathrm{V}$ was connected to the outlet and thus only expired air passed thru the valve (, filled symbols), the reported $\mathrm{O}_{2}$ uptake fell considerably. 

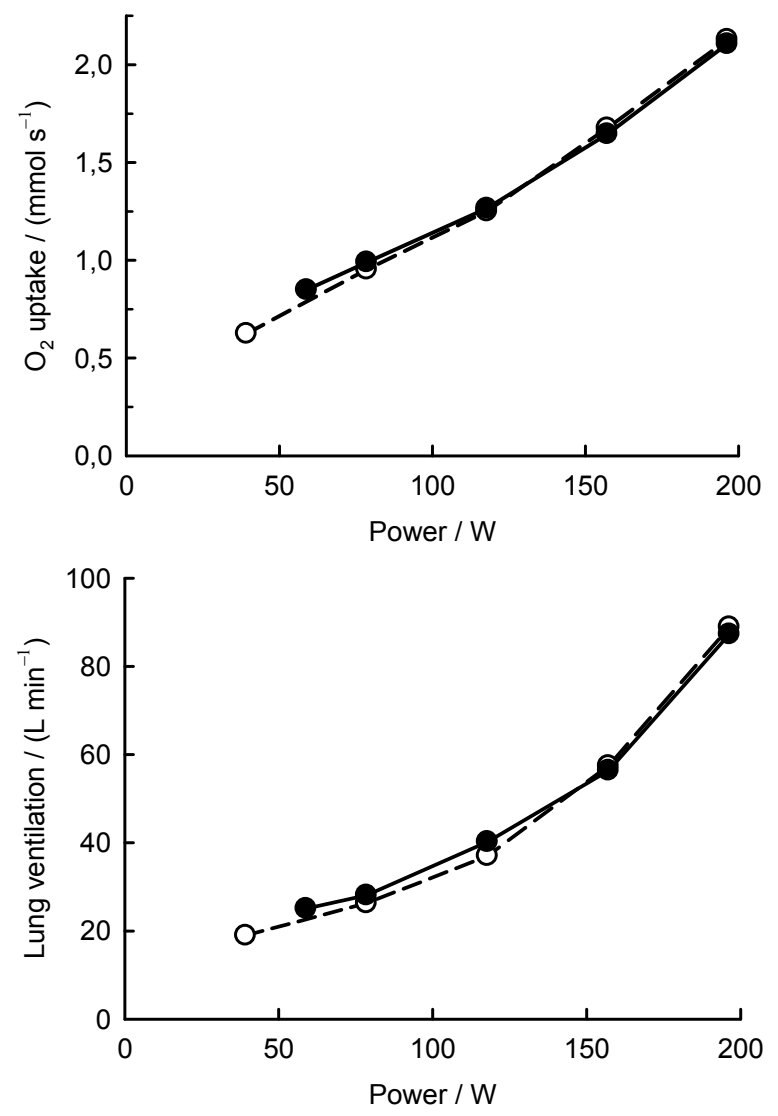

Figure 4. Top panel, $\mathrm{O}_{2}$ uptake measured by the Metamax II versus power during cycling at stepwise increasing power. Lower panel, lung ventilation versus power during the same exercises. The data are from a subject who cycled for $5 \mathrm{~min}$ at each power. During one series the subject inspired from bottles with pressurised air, and the Metamax II was modified to produce an artificial inspiration signal after every expirations when only expired air was passed through the breathing valve $(\mathbf{O}$, filled symbols). In control experiments the subjects cycled while using the Metamax II in its normal mode. This means that both inspired and expired air passed through the breathing valve $(\bigcirc$, open symbols). 


\section{DISCUSSION}

The Metamax II metabolic system requires an inspiration signal between two consecutive expirations to work properly. In our study the reported $\mathrm{O}_{2}$ uptake fell by around $50 \%$ when the instrument did not receive inspiration signals. By producing an artificial inspiration signal between two consecutive expirations, the instrument worked properly when the subject only expired through the instrument's breathing valve.

This study is not the first to sample expired air from subjects breathing from a self-contained breathing apparatus (SCBA), but former studies did not measure the $\mathrm{O}_{2}$ uptake at hot and polluted conditions. Eves and co-workers [4] mounted a cone of Plexiglas providing an airtight seal around the outlet of the SCBA regulator used, and expired air was led to their metabolic analyser. Several other studies have measured the $\mathrm{O}_{2}$ uptake on exercising subjects using a breathing apparatus $[1-3,7,11-13]$, apparently by simply collecting expired air from the outlet of the breathing apparatus used. In our case we had to produce an artificial inspiration signal to make the Metamax II metabolic system work properly. We have in addition provided heat protection by insulating the instrument, and further protecting it from mechanical impacts. The latter remedies allow us to measure the $\mathrm{O}_{2}$ uptake while firefighters work in hot and polluted environments. This has to our knowledge not been done earlier, probably because heat may damage metabolic analyzers $[5,10]$. We also filtered out minor rotations of the fan, rotations that may occur for reasons other than respiration. Such small movements may readily appear both at rest and during exercise, particularly during exercise of moderate intensity with moderate, regular breathing with some interval between the end of expiration and the start of a new inspiration. The filtering introduced may be important since that made the instrument's software more robust against noise. Our software required $0.67 \mathrm{~s}$ between the end of one expiration and the start of a new one. That should be problem for firefighters using a breathing apparatus since the apparatus does not allow extremely high ventilations. However, top athletes may breathe as much as $200 \mathrm{~L} / \mathrm{min}$ with a breathing frequency above $1 \mathrm{~Hz}$. In that case our modification of the Metamax will fail.

We conclude that with proper modifications of the Metamax II, the instrument allows measurements of the $\mathrm{O}_{2}$ uptake when only expired 
air passes through the breathing valve. The heat protections introduced may allow measurements of the $\mathrm{O}_{2}$ uptake during exercise in hot and polluted environments.

This study is part of a larger study approved by the Ethics Committee of Health Region 4 in Norway.

\section{REFERENCES}

1. Donovan, K. J., McConnell, A. K. (1999) Fire-fighters' selfcontained breathing apparatus (SCBA): The effects of SCBA mass upon exercise duration during treadmill walks in the laboratory. Fire Engineers Journal 59: 23-33.

2. Dreger, R. W., Jones, R. L., Petersen, S. R. (2006) Effects of the selfcontained breathing apparatus and fire protective clothing on maximal oxygen uptake. Ergonomics 49: 911-920

3. Eves, N. D., Jones, R. L., Petersen, S. R. (2005) The influence of the self-contained breathing apparatus (SCBA) on ventilatory function and maximal exercise. Can. J. Appl. Physiol. 30: 507-519

4. Eves, N. D., Petersen, S. R., Jones, R. L. (2002) Hyperoxia improves maximal exercise with the self-contained breathing apparatus (SCBA). Ergonomics 45: 829-839

5. Holmer, I., Gavhed, D. (2007) Classification of metabolic and respiratory demands in fire fighting activity with extreme workloads. Appl. Ergon. 38: 45-52

6. Krogh, A. (1913) A bicycle ergometer and respiration apparatus for the experimental study of muscular work. Skand. Arch. Physiol. 30: 375-394

7. Louhevaara, V., Smolander, J., Korhonen, O., Tuomi, T. (1986) Maximal working times with a self-contained breathing apparatus. Ergonomics 29: 77-85

8. Medbø, J. I. (2002) Examination of the time response of the Metamax I and II metabolic analysers at the onset and end of exercise. Acta Kinesiol. Univ. Tartuensis 7: 50-60

9. Medbø, J. I., Mamen, A., Welde, B., von Heimburg, E. D., Stokke, R. (2002) Examination of the Metamax I and II oxygen analysers during exercise studies in the laboratory. Scand. J. Clin. Lab. Invest. 62: $585-598$

10. Perroni, F., Tessitore, A., Cortis, C., Lupo, C., D'artibale, E., Cignitti, L., Capranica, L. (2010) Energy cost and energy sources during 
a simulated firefighting activity. J. Strength. Cond. Res. 24: 34573463

11. Sothmann, M. S., Saupe, K. W., Jasenof, D., Blaney, J., Fuhrman, S. D., Woulfe, T. (1990) Advancing age and the cardiorespiratory stress of fire suppression: Determining a minimum standard for aerobic fitness. Human Performance 3: 217-236

12. Williams-Bell, F. M., Boisseau, G., McGill, J., Kostiuk, A., Hughson, R. L. (2010) Air management and physiological responses during simulated firefighting tasks in a high-rise structure. Appl. Ergon. 41: 251-259

13. Williams-Bell, F. M., Boisseau, G., McGill, J., Kostiuk, A., Hughson, R. L. (2010) Physiological responses and air consumption during simulated firefighting tasks in a subway system. Appl. Physiol Nutr. Metab 35: 671-678

\section{Correspondence to:}

Jon Ingulf Medbø

National Institute of Occupational Health

PO Box 8149 dep., NO-0033 Oslo

Norway

E-mail: Jon.Medbo@stami.no 